\title{
Predation preference and nutritional values of four different aphid species for Orius sauteri (Hemiptera: Anthocoridae)
}

\author{
Liu Zhang ${ }^{1}{ }^{1}$, Tao Li ${ }^{1}$, Zifang Qin ${ }^{1}$, Kaili Cao ${ }^{1}$, Yifan Gao ${ }^{1}$, Jingyi Wang ${ }^{1}$, Yang Ge ${ }^{2}$ and Wangpeng Shi*
}

\begin{abstract}
Background: Orius sauteri (Poppius) is one of the important natural enemies of aphids in Asia. Understanding its predation preference and efficiency can help improve its effectiveness as a biological control agent. Here, the predation preference of O. sauteri adults toward Aphis craccivora Koch, Rhopalosiphum maidis (Fitch), Myzus persicae Sulzer, and Aphis gossypii Glover was studied.

Results: The research found that $O$. sauteri had good predation efficiency on four important aphid species. Orius sauteri killed a similar number of four aphids in non-selective tests, but it preferred to eat more R. maidis and A. gossypii, and fewer A. craccivora in selective tests. The main biochemical components of the four aphid species were analyzed, including water content and nutritional components along with body mass. Rhopalosiphum maidis had a significantly lower water content than A. craccivora. Orius sauteri preferred $R$. maidis and A. gossypii, which harbored higher lipid and trehalose content, while preying on fewer A. craccivora, which had a larger body weight for the supplement of water and nutrition. The predation preference may be due to the closest nutrition composition to the optimal intake of $O$. sauteri.
\end{abstract}

Conclusions: This study showed that the predatory selection of O. sauteri was closely associated with the water content, bodyweight, lipid, and trehalose levels of prey, while the glycogen content and protein level might be less determinant. The high predation capacity on four aphids of $O$. sauteri indicated the great potential to integrate this predator into biological control strategies against aphids.

Keywords: Aphids, Orius sauteri, Prey preference, Nutritional analysis, Trehalose

\section{Background}

Studying predators' behavior is important to understand how the predators live and how they affect the population dynamics of their prey (Dixon 2000). Predators attack prey selectively and feed on a subset of prey that they encounter (Waldbauer and Friedman 1991; Klecka and Boukal 2012). According to the optimal foraging theory, individuals behave in a way to obtain

\footnotetext{
*Correspondence: wpshi@cau.edu.cn

1 Department of Entomology and MOA Key Laboratory of Pest Monitoring and Green Management, College of Plant Protection, China Agricultural University, Beijing 100193, China

Full list of author information is available at the end of the article
}

food resources required for survival and reproduction while expending the least amount of time (Pyke et al. 1977), which posits that predators should maximize their energy intake by selectively preying on the most beneficial resources. The energy obtained from prey has been the main prey currency influencing the foraging behavior of predators (Whelan and Schmidt 2007). However, this theory fails when applied to predator species that feed on moving prey or place excessive emphasis on their energy intake instead of the prey's nutritional composition (Sih and Christensen 2001; Kohl et al. 2015). Predators do not use prey only as a source of energy, but also to obtain building blocks for their tissues (Raubenheimer et al. 2009). More recently, 
studies have documented that water and nutrients, including carbohydrates, proteins, and lipids, play important roles in animal foraging decisions and foodweb ecology (Fagan et al. 2002; Sterner and Elser 2002; McCluney and Sabo 2009, 2016; Schmidt et al. 2012; Simpson and Raubenheimer 2012; Wilder et al. 2013; Allen et al. 2014; Deguines et al. 2017; McCluney 2017).

The minute pirate bug, Orius sauteri (Poppius) (Hemiptera: Anthocoridae), is an important biological control agent for numerous agricultural pests in Asia (Yano 1996; Yano et al. 2005). Orius sauteri can regulate many economically important arthropod pests, including mites (Sun et al. 2009), whiteflies (Yano et al. 2005; Wang et al. 2013), thrips (Nagai and Yano 2000; Liu et al. 2011a), and aphids (Nakata 1995). Notably, O. sauteri often appears in corn and cotton fields feeding on aphids and thrips (Cui 1994; Zou 2004).

Aphids (Hemiptera: Aphididae) are important agricultural pests and pose a serious threat to the quality and yield of crops, causing huge economic losses. In addition to causing direct damage through their feeding behavior, aphids also transmit plant pathogenic viruses. The cosmopolitan cowpea aphid, Aphis craccivora (Koch), is a holocyclic, heteroecious species that infests eight plant families and transmits over fifty kinds of plant viruses (Stoetzel and Miller 2001). Yield loss of more than $50 \%$ occurs when high infestations of cowpea aphids are not controlled in the production of cowpea (Obopile 2006). The corn leaf aphid, Rhopalosiphum maidis (Fitch), is the most economically damaging aphid pest on maize and an important vector of several destructive maize viruses, including barley yellow dwarf virus, maize yellow dwarf virus, sugarcane mosaic virus, and cucumber mosaic virus (El-Muadhidi et al. 2001; Hawkes and Jones 2005; Jarosova et al. 2013; Power et al. 2011; Krueger et al. 2013). The cotton aphid, Aphis gossypii Glover, is a polyphagous herbivore that causes serious damage to many plants, including cucumber (Cucumis sativus Linn), okra (Abelmoschus spp.), and cotton (Gossypium herbaceum Linn) (Zhang et al. 2020). The green peach aphid or peach potato aphid, Myzus persicae Sulzer, is a worldwide distributed aphid crop pest. It is highly polyphagous, with a host range of more than 400 species in 40 different plant families, and causes indirect damage to its host by its capability of transmitting over 100 different plant viruses (Blackman and Eastop 2000).

The aim of the present study was to study the preferences of the predatory $O$. sauteri on four different aphids, A. craccivora, R. maidis, M. persicae, and A. gossypii, which are all important aphids. Also, explore the reasons behind the selective predation of the aspects of water content, body weight, and nutritional components.

\section{Methods}

\section{Insects rearing}

Original colonies of O. sauteri were collected from corn plants in the China Agricultural University's experimental field in Beijing, China. Laboratory colonies of O. sauteri were fed on Sitotroga cerealella (Olivier) eggs attached to Post-it notes along with green bean pods for oviposition, with some buckwheat hulls as shelter. Insects were reared in an incubator under conditions of $25 \pm 2{ }^{\circ} \mathrm{C}, 70 \pm 5 \% \mathrm{R} . \mathrm{H}$. (relative humidity), and $16: 8 \mathrm{~h}$ (L:D) photoperiod cycle (Ge et al. 2018). Colonies of four aphid species were originally initiated with insects collected from the experimental field of China Agricultural University. Aphis craccivora was mass reared on broad bean plants (Vicia faba L.). Rhopalosiphum maidis was reared on the corn plants. Aphis gossypii was reared on cotton plants, and $M$. persicae was reared on pepper seedlings. The host plants were grown in plastic pots filled with a mix of nutrient soil and vermiculite (1:1). All of the aphid colonies were kept in a controlled chamber $\left(20 \pm 1{ }^{\circ} \mathrm{C}, 75 \pm 5 \%\right.$ R.H., 16L:8D). Nymphal aphids were used for the experiments.

\section{Non-selective and selective predation of Orius sauteri}

In all predation experiments, as suggested by Nakamura (1977), the 3-day-old female of O. sauteri adults was individually placed in vials and starved for $24 \mathrm{~h}$ before the experiment to maximize individual hunger levels. The nymph aphids were introduced in plastic Petri dishes (diameter $=9 \mathrm{~cm}$ ) before the predator so that they could disperse and the predators might have to search for the aphids. The predator was removed from the dish, and the number of aphids killed by the predator was recorded in each Petri dish after $24 \mathrm{~h}$. All these experiments were performed at $25{ }^{\circ} \mathrm{C}, 65 \pm 5 \% \mathrm{R}$. H. and a photoperiod of 16L:8D.

For the non-selective predation assay, 60 individuals of each of the four different aphid species were assayed separately. The predators were introduced individually into the Petri dishes which contained specific amounts of aphids per Petri dish along with corresponding host plant leaves.

For the selective predation assay, fifteen aphids of similar body size to each species were mixed together as prey. Orius sauteri was introduced individually into the Petri dishes for predation.

\section{Aphids' weight and water content}

A group of 50 aphids of each species of similar body size was collected in different sample vials. The fresh weight of each sample was measured using an electronic scale (TP-114, Denver Instrument, USA). The dry weight of four aphid species was obtained by oven drying at $65^{\circ} \mathrm{C}$ 
until a constant weight was achieved, and then, water content was calculated. These aphids were used for total lipid, glycogen, trehalose, and soluble protein content analyses as well. There were nine replicates for each aphid species.

\section{Nutritional components analysis}

The total lipid, glycogen, trehalose, and soluble protein of the four aphid species were extracted based on a slightly modified extraction method of Zhou et al. (2004) and Shi et al. (2010). Total lipid was assayed by using a triolein (Sigma-Aldrich, St. Louis, MO, USA) as a quantitative standard (Van Handel 1985b; Van Handel and Day 1988). The glycogen and trehalose content was measured using the anthrone method (Van Handel 1985a) with glycogen and trehalose standards purchased from Sigma Chemical Co. Soluble protein was determined by the method of Shi et al. (2010) using the BCA Protein Assay Kit (Biosynthesis Biotechnology Company, Beijing, China). The total lipid, soluble protein, glycogen, and trehalose content of different aphid species was quantified separately by a spectrophotometer at a $525 \mathrm{~nm}, 562 \mathrm{~nm}, 625 \mathrm{~nm}$, and $625 \mathrm{~nm}$ wavelength, respectively. There were five to nine replicates of different aphid species for each nutrient.

\section{Statistical analysis}

The predation capability of O. sauteri, water content, fresh and dry weights, and nutritional contents against the fresh weight of four aphid species was compared by one-way analysis of variance (ANOVA) followed by LSD (Least Significant Difference) test with $\alpha=0.05$. All data were analyzed using SPSS V20.0. (IBM Corp., Armonk, NY, USA).

\section{Results}

\section{Non-selective and selective predation of Orius sauteri}

The results indicated that there was no significant difference among the predation capabilities of $O$. sauteri on A. craccivora, $R$. maidis, M. persicae, and A. gossypii in the non-selective experiment $\left(F_{3,11}=0.717, P=0.569\right.$; Fig. 1). However, O. sauteri females showed a significant predatory preference in the selective test $\left(F_{3,11}=5.819\right.$, $P=0.021$; Fig. 2). Orius sauteri killed the largest number of $R$. maidis and the fewest A. craccivora among the four species. There was a remarkable difference in the consumption of $O$. sauteri by $A$. craccivora compared to $R$. maidis and A. gossypii.

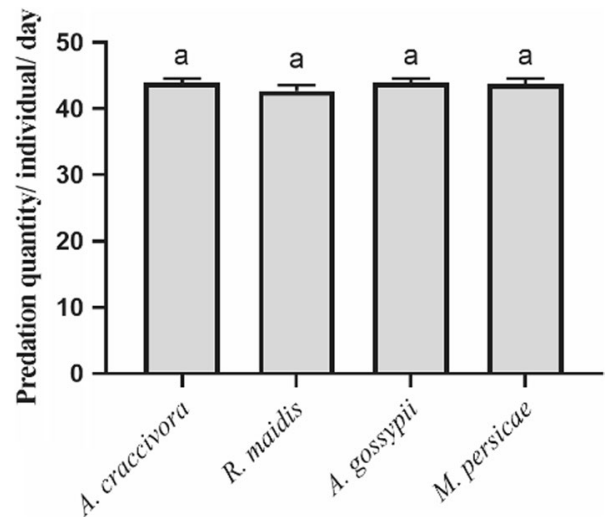

Fig. 1 Non-selective predation of Orius sauteri on the four aphid species. Values are mean \pm SE (Standard Error). The data were compared by ANOVA followed by LSD test with $a=0.05$, and means indicated by the same letter are not significantly different

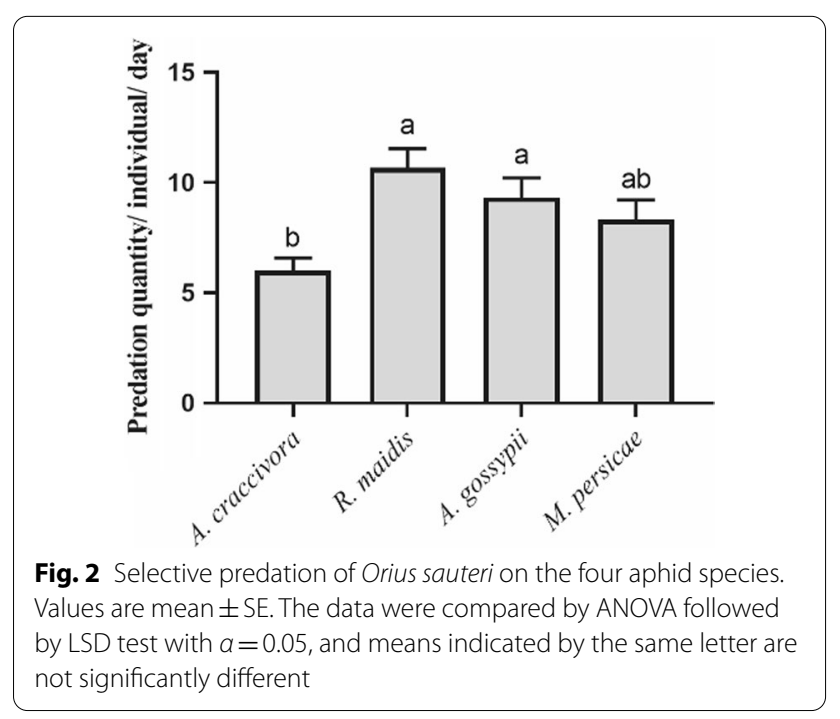

Water content and bodyweight of four aphid species The water content of $R$. maidis $(67.40 \%)$ was significantly lower compared to A. craccivora (75.77\%), $M$. persicae (79.91\%), and A. gossypii (75.30\%) $\left(F_{3,35}=9.107, P<0.001\right.$; Fig. 3a). There was no significant difference among these three aphid species.

The rank of fresh and dry weights of four aphid species showed similar patterns. The fresh and dry weight of A. craccivora was both the highest among the four aphid species, and they were significantly higher than the other three aphid species. (Fresh weight: $F_{3,35}=207.432, P<0.001$; Fig. 3 b; Dry weight: $F_{3,35}=260.861, P<0.001$; Fig. $3 c$ ). The fresh and dry weight of $R$. maidis was significantly higher than those of M. persicae and A. gossypii, and there were 

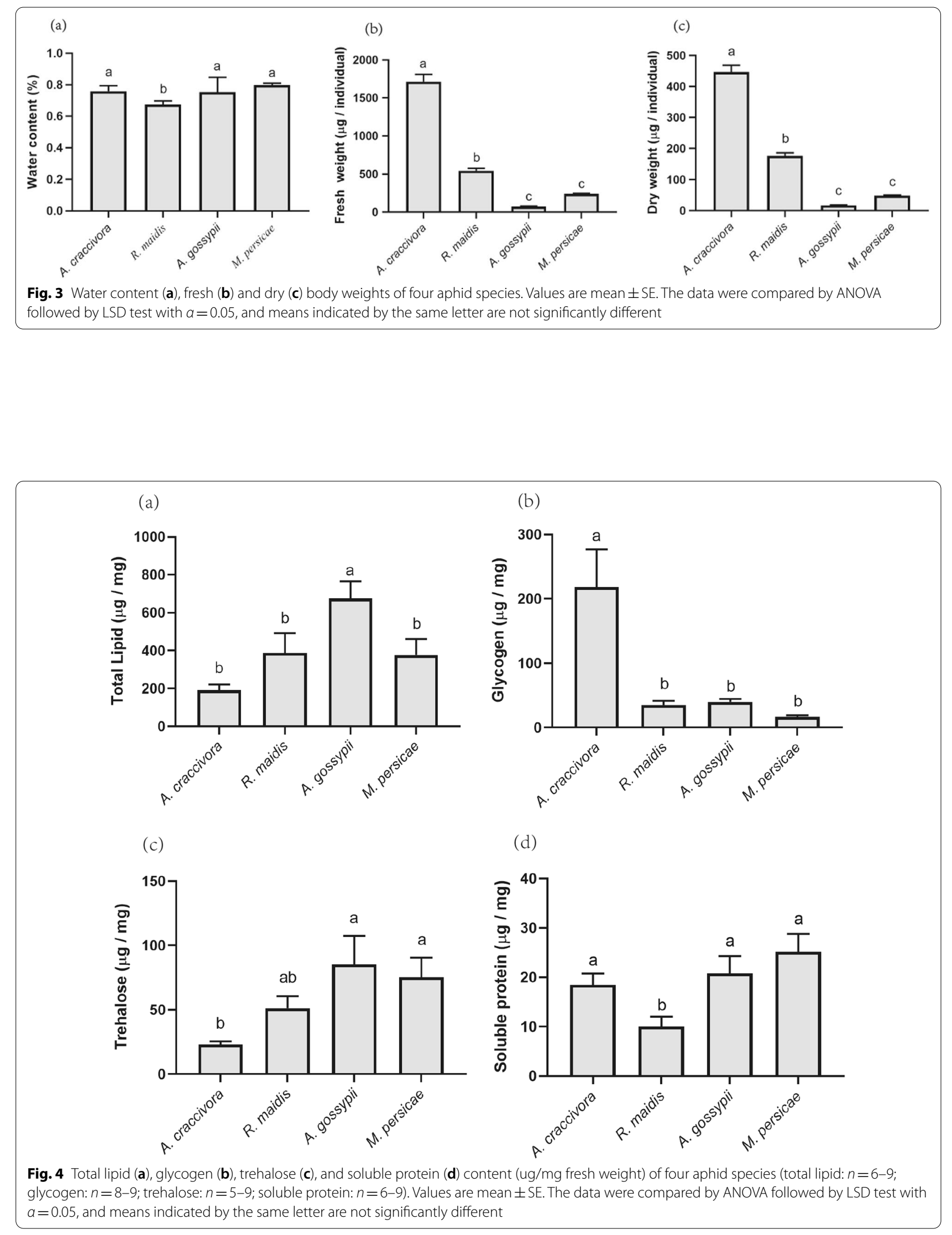
no significant differences between $M$. persicae and $A$. gossypii.

\section{Nutritional components of four aphid species}

The total lipid level against an aphid's fresh weight in $R$. maidis and $A$ gossypii was significantly higher than that in $A$. craccivora $\left(F_{3,31}=3.629, P=0.025\right.$; Fig. $\left.4 a\right)$. The total lipid level in Aphis craccivora was the lowest, but it was not different from that in M. persicae. Aphis craccivora showed a significantly lower trehalose level than the other three aphid species $\left(F_{3,30}=3.855 ; P=0.020\right.$; Fig. 4c). In addition, $A$. craccivora contained 5-16 higher glycogen levels than the other three aphid species $\left(F_{3,34}=11.318 ; P<0.001\right.$; Fig. $\left.4 \mathrm{~b}\right)$. There was no significant difference in soluble protein content among the four aphid species $\left(F_{3,29}=1.264 ; P=0.307\right.$; Fig. $\left.4 \mathrm{~d}\right)$.

\section{Discussion}

Orius sauteri, as a generalist predator, demonstrated remarkable behavioral and physiological adaptability in response to a variety of food resources (Liu et al. 2011a, b). Previous research has shown that aphids are an appropriate prey for O. sauteri (Wang et al. 2014). In this study, $O$. sauteri females had similar predation capabilities on A. craccivora, R. maidis, M. persicae, and A. gossypii in the non-selective experiment. Alvarado et al. (1997) reported the maximum consumption of Orius laevigatus (Fieber) and Orius majusculus (Reuter) on A. gossipii was $17 \pm 2.09$ and $21.1 \pm 2.41$, respectively, in $24 \mathrm{~h}$., which is apparently lower than our results $(44.0 \pm 0.58$; Fig. 1). Ge et al. (2018) tested the predation of $A$. craccivora by $O$. sauteri under different temperatures, and the consumption was similar to present study results in the same condition and prey density. Based on these results, we assume that $O$. sauteri does present strong predation on these aphids even compared with other important predators of Anthocoridae species. Surprisingly, there was no significant difference in the consumption of $O$. sauteri in $24 \mathrm{~h}$ on four aphid species, which could be explained by $O$. sauteri's behavioral and gustatory suitability to these four aphid species. When O. sauteri was provided with prey options, notably higher consumption of $R$. maidis, and A. gossypii was identified compared to A. craccivora. However, it has not been reported on the biochemical mechanism of the selective predation of $O$. sauteri adults on these four aphid species. Here, we studied the main biochemical components of the four aphid species, including water content and nutritional components along with bodyweight. The result showed that the predatory selection of $O$. sauteri was closely related to the water content, body weight, lipid, and trehalose content of prey, while glycogen and protein content might be less determinant in this case.
Orius sauteri is a small piercing-sucking predator. Thus, the water content and body size of prey are important for prey selection. Rhopalosiphum maidis, with a significantly lower water content compared to the other three aphids, may contain more necessary nutrient substances to meet the demands of specific nutritional requirements for the development of predators. Compared to A. craccivora, which has the largest body size, and the heaviest body mass, the other three relatively small-sized aphids seemed to be easier captured by $O$. sauteri. The finding of Farhoudi et al. (2014) showed that aphid size is a more important factor than color in contributing to the predation preference of Aphidoletes aphidimyza (Rondani). Predators and parasites usually select small prey as preferred food, and that might be due to the low defensive capabilities and short handling times (Allan et al. 1987; Reitz et al. 2006). In addition to the size of prey, predation characteristics like prey handling ability and prey encounter rate are considered to be positively influenced by the size of the predator (Farhoudi et al. 2014). Orius sauteri, as the predator in our research, which has a small body size might try to avoid relatively large prey which is consistent with many previous studies (Schmidt et al. 2012; Farhoudi et al. 2014; Allan et al. 1987Reitz et al. 2006).

The extremely high glycogen content in A. craccivora might not contribute to the predation preference of $O$. sauteri, which suggests the glycogen content in other aphid species can meet the demands of $O$. sauteri. The nutrient composition (carbohydrates, proteins, lipids) of prey, its elemental composition such as the C:N:P ratio, or essential micronutrient content such as the long-chain polyunsaturated fatty acids relative to the needs of a predator thus provides a more realistic basis for studies of selective predation (Guo et al. 2018). Previous researchers hypothesized that multiple nutrient compositions close to the predator's optimal demands which include some particularly rich critical nutrients may contribute to the preferred predation (Schmidt et al. 2012; Raubenheimer and Simpson 2003). Thus, R. maidis and $A$ gossypii, as the preferred preys of $O$. sauteri among the four aphids, might have a nutrient composition that is closest to the optimal intake composition of O. sauteri. The total lipid level against an aphid's fresh weight in $R$. maidis and $A$ gossypii was significantly higher than that in A. craccivora, and that is consistent with the predational preference of $O$. sauteri adults. Orius sauteri showed less preference to A. craccivora probably because of their low content of some particular crucial substances such as lipid and trehalose. Different prey species exert distinct effects on the development and reproduction of predators, which may contribute to the preference of predators on prey (Calixto et al 2013). The physiological 
and nutritional mechanisms need to be explored further (Raubenheimer et al. 2009; Mayntz and Toft 2001). There is accumulating evidence that nutrition has a prominent influence on trophic interactions, and combining more detailed dietary information with studies of food webs could give us a much deeper understanding of the structure and function of communities and ecosystems (Muller-Navarra 2008). The feeding preference of O. sauteri is likely to be correlated with the profitability of energy substances in its metabolic processes. It has been proved that trehalose is the dominant sugar in the hemolymph and other tissues of insects as it provides energy for targeted activities (Van Handel 1969; Lu et al. 2019). Egg-laying by insects is closely related to trehalose levels. Huang and Lee (2011) found that the production of oocysts would be delayed by decreasing trehalose levels, suggesting that trehalose is a key energy source during spawning. The addition of an appropriate amount of trehalose or glucose may have a positive effect on the growth, development, and reproduction of Harmonia axyridis (Pallas) (Coleoptera: Coccinellidae) (Li et al. 2020). Schmidt et al. (2012) found the spider Pardosa milvina (Araneae: Lycosidae) could discriminate against different prey based only on their nutrient content. The activity of insects has a close relationship with their energy metabolism (Wong et al. 2016). Predators are sensitive to their nutritional needs, and based on that, predators decide whether to capture a particular prey or not so as to regulate the amount of their food intake to satisfy their metabolic needs (Mayntz et al. 2005). Li and Jackson (1997) demonstrated that there are long-term benefits for predators in many aspects when predator Portia fimbriata (Araneae: Salticidae) feeds on preferred prey, such as a faster developmental rate, larger body size at maturation, and especially a higher survival rate than when feeding on less-preferred prey. Considering these, the preferred prey chosen by $O$. sauteri might also have long-term potential physiological benefits for the predator.

The protein leverage effect hypothesis predicts that consumers will not stop feeding until they reach the intake level of a specific target protein (Raubenheimer et al 2009; Simpson and Raubenheimer 2005). Thus, consumers have to hunt more prey in order to maintain protein intake and get similar amounts of protein obtained from higher protein level prey. The finding of Farhoudi et al. (2014) showed that predatory gall midges consumed more red aphids, which have lower protein levels (Ahsaei et al. 2013) than green ones of the same size. Here, we found that $R$. maidis had the lowest protein level among the four aphids. However, the content may have a negligible effect on the prey preference of $O$. sauteri in this study, because there was no significant difference in soluble protein content among the four aphid species.
Generally, females of Orius spp. consume significantly more prey and have a bigger effect on the offspring than males do (Tanaka et al. 2002). However, further studies on sex differences in selective predation may be needed to get a better understanding of the foraging behavior of O. sauteri.

We also found that the number of prey corpses was merely partially consumed, which suggests that $O$. sauteri killed extra aphids than they could consume. Similar findings were also reported in other studies (Alvarado et al. 1997; Lang and Gsodl 2003; Maupin and Riechert 2001). For example, Alvarado et al. (1997) found prey $A$. gossipii, which was predated by four predatory bugs, was killed and partially consumed. Superfluous killing behavior was also found in spiders, and it was presumed that the superfluous killing behavior indicates the predators' adaptation to food-limited environments (Maupin and Riechert 2001). This predatory behavior of $O$. sauteri in one way or another may contribute to better control of aphids in the field. Further studies are needed to check the numbers and status of corpses for different preys, and the handling abilities of different preys, which will help us get a better understanding of the feeding habits of $O$. sauteri.

\section{Conclusions}

In conclusion, Orius sauteri had good predatory effects on four important aphid species. Predatory selection was closely associated with the differences in body size, water and nutritional content, especially the lipid and trehalose levels of different aphid species. Females of O. sauteri preferred $R$. maidis and A. gossypii, which contain significantly more lipid and trehalose than A. craccivora. $R$. maidis also has lower water content. Our research may help understand the biochemical mechanism of selective predation of $O$. saureri, and tries to prompt further evaluation of the predatory potential of $O$. sauteri as an effective biological control agent for four important aphids. Further studies of predatory interaction between $O$. sauteri and its prey need to be thoroughly explored in the future.

\section{Acknowledgements \\ Not applicable.}

\section{Authors' contributions}

TL involved in conceptualization; TL took part in methodology; Tl involved in validation; $\mathrm{LZ}$ and ZQ took part in formal analysis; ZQ, KC, and TL took part in investigation; $Y G$ and $Y W$ involved in resources; $L Z$ took part in writing-original draft preparation; WS and LZ involved in writing — review and editing; LZ involved in visualization; WS took part in supervision; WS took part in project administration; WS involved in funding acquisition. All authors have read and agreed to the published version of the manuscript.

\section{Funding}

This research was funded by the [National Li Chanye Jishu Tixi], grant number [CARS-29-05B]. 


\section{Availability of data and materials}

The datasets used and/or analysed during the current study are available fromthe corresponding author on reasonable request.

\section{Declarations}

\section{Ethics approval and consent to participate}

Not applicable.

\section{Consent for publication}

Not applicable.

\section{Competing interests}

The authors declare that they have no competing interests.

\section{Author details}

${ }^{1}$ Department of Entomology and MOA Key Laboratory of Pest Monitoring and Green Management, College of Plant Protection, China Agricultural University, Beijing 100193, China. ${ }^{2}$ National Resource Center for Chinese Materia Medica, China Academy of Chinese Medical Sciences, State Key Laboratory Breeding Base of Dao-Di Herbs, Beijing 100700, China.

Received: 28 October 2021 Accepted: 3 March 2022

Published online: 08 March 2022

\section{References}

Ahsaei SM, Tabadkani SM, Hosseininaveh V, Allahyari H, Bigham M (2013) Differential accumulation of energy by the colour morphs of the pea aphid Acyrthosiphon pisum (Hemiptera: Aphididae) mirrors their ecological adaptations. Eur J Entomol 110(2):241-245. https://doi.org/10.14411/eje. 2013.035

Allan JD, Flecker AS, McClintock NL (1987) Prey preference of stoneflies: sedentary vs mobile prey. Oikos 49(3):323-331. https://doi.org/10.2307/ 3565768

Allen DC, McCluney KE, Elser SR, Sabo JL (2014) Water as a trophic currency in dryland food webs. Front Ecol Environ 12(3):156-160. https://doi.org/10. 1890/130160

Alvarado P, Balta O, Alomar O (1997) Efficiency of four Heteroptera as predators of Aphis gossypii and Macrosiphum euphorbiae (Hom.: Aphididae). Entomophaga 42(1-2):215-226. https://doi.org/10.1007/BF02769899

Blackman RL, Eastop VF (2000) Aphids on the world's crops, an identification and information guide, 2nd edn. Wiley, Chichester

Calixto AM, Bueno VHP, Montes FC, Silva AC, Van Lenteren JC (2013) Effect of different diets on reproduction, longevity and predation capacity of Orius insidiosus (Say) (Hemiptera: Anthocoridae). Biocontrol Sci Technol 23(11):1245-1255. https://doi.org/10.1080/09583157.2013.822850

Cui SZ (1994) Studies on biological characteristics of Orius minutus and its control of major cotton insect pests. Acta Gossypii Sinica S1:78-83

Deguines N, Brashares JS, Prugh LR (2017) Precipitation alters interactions in a grassland ecological community. J Anim Ecol 86(2):262-272. https://doi. org/10.1111/1365-2656.12614

Dixon AFG (2000) Insect predator-prey dynamics ladybird beetles and biological control. Cambridge University Press, Cambridge

El-Muadhidi MA, Makkouk KM, Kumari SG, Jerjess M, Murad SS, Mustafa RR, Tarik F (2001) Survey for legume and cereal viruses in Iraq. Phytopathol Mediterr 40(3):224-233

Fagan WF, Siemann E, Mitter C, Denno RF, Huberty AF, Woods HA, Elser JJ (2002) Nitrogen in insects: implications for trophic complexity and species diversification. Am Nat 160(6):784-802. https://doi.org/10.1086/ 343879

Farhoudi F, Allahyari H, Tabadkani SM, Gholizadeh M (2014) Prey preference of Aphidoletes Aphidimyza on Acyrthosiphon Pisum: effect of prey color and size. J Insect Behav 27(6):776-785. https://doi.org/10.1007/ s10905-014-9470-4

Ge Y, Camara I, Wang Y, Liu P, Zhang L, Xing Y, Li A, Shi W (2018) Predation of Aphis craccivora (Hemiptera: Aphididae) by Orius sauteri
(Hemiptera: Anthocoridae) under different temperatures. J Econ Entomol 6(111):2599-2604. https://doi.org/10.1093/jee/toy255

Guo F, Bunn SE, Brett MT, Fry B, Hager H, Ouyang X, Kainz MJ (2018) Feeding strategies for the acquisition of high-quality food sources in stream macroinvertebrates: collecting, integrating, and mixed feeding. Limnol Oceanogr 63(5):1964-1978. https://doi.org/10.1002/Ino.10818

Hawkes JR, Jones RAC (2005) Incidence and distribution of barley yellow dwarf virus and cereal yellow dwarf virus in over summering grasses in a Mediterranean-type environment. Aust J Agric Res 56(3):257-270. https:// doi.org/10.1071/AR04259

Huang JH, Lee HJ (2011) RNA interference unveils functions of the hypertrehalosemic hormone on cyclic fluctuation of hemolymph trehalose and oviposition in the virgin female Blattella germanica. J Insect Physiol 57(7):858-864. https://doi.org/10.1016/j.jinsphys.2011.03.012

Jarosova J, Chrpova J, Sip V, Kundu JK (2013) A comparative study of the Barley yellow dwarf virus species PAV and PAS: distribution, accumulation and host resistance. Plant Pathol 62(2):436-443. https://doi.org/10.1111/j. 1365-3059.2012.02644.x

Klecka J, Boukal DS (2012) Who eats whom in a pool? PLoS ONE, A comparative study of prey selectivity by predatory aquatic insects. https://doi.org/ 10.1371/journal.pone.0037741

Kohl KD, Coogan SC, Raubenheimer D (2015) Do wild carnivores forage for prey or for nutrients? Evidence for nutrient-specific foraging in vertebrate predators. BioEssays 37(6):701-709. https://doi.org/10.1002/bies.20140 0171

Krueger EN, Beckett RJ, Gray SM, Miller WA (2013) The complete nucleotide sequence of the genome of barley yellow dwarf virus-RMV reveals it to be a new polerovirus distantly related to other yellow dwarf viruses. Front Microbiol 4:205. https://doi.org/10.3389/fmicb.2013.00205

Lang A, Gsodl S (2003) "Superfluous killing" of aphids: a potentially beneficial behaviour of the predator Poecilus cupreus (L.) (Coleoptera: Carabidae)? J Plant Dis Prot 110(6):583-590

Li DQ, Jackson RR (1997) Influence of diet on survivorship and growth in Portia fimbriata, an Araneophagic jumping spider (Araneae: Salticidae). Can J Zool Rev Can Zool 75(10):1652-1658. https://doi.org/10.1139/z97-792

Li Y, Wang SS, Liu YK, Lu YT, Zhou M, Wang S, Wang SG (2020) The effect of different dietary sugars on the development and fecundity of Harmonia axyridis. Front Physiol. https://doi.org/10.3389/fphys.2020.574851

Liu WJ, Zhang AS, Men XY, Zhou XH, Li LL, Zhang SC, Yu Y, Xu HF (2011a) Effect of two different preys on predation of Orius sauteri (Heteroptera: Anthocoridae). Chin J Biol Control 27(3):302-307

Liu WJ, Zhang AS, Li LL, Men XY, Zhang SC, Zhou XH, Yu Y, Xu HF (2011 b) Effect of two live diets on the development and reproduction of Orius sauteri (Heteroptera: Anthocoridae). Chin J Appl Entomol 48(3):566-568

Lu K, Wang Y, Chen X, Zhang XY, Li WR, Cheng YB, Li Y, Zhou JM, You KK, Song YY, Zhou Q, Zeng RS (2019) Adipokinetic hormone receptor mediates trehalose homeostasis to promote vitellogenin uptake by oocytes in Nilaparvata lugens. Front Physiol 9:1904. https://doi.org/10.3389/fphys. 2018.01904

Mayntz D, Raubenheimer D, Salomon M, Toft S, Simpson SJ (2005) Nutrientspecific foraging in invertebrate predators. Science 307(5706):111-113. https://doi.org/10.1126/science.1105493

Mayntz D, Toft S (2001) Nutrient composition of the prey's diet affects growth and survivorship of a generalist predator. Oecologia 127(2):207-213. https://doi.org/10.1007/s004420000591

Maupin JL, Riechert SE (2001) Superfluous killing in spiders: A consequence of adaptation to food-limited environments? Behav Ecol 12(5):569-576. https://doi.org/10.1093/beheco/12.5.569

McCluney KE, Sabo JL (2009) Water availability directly determines per capita consumption at two trophic levels. Ecology 90(6):1463-1469. https://doi. org/10.1890/08-1626.1

McCluney KE, Sabo JL (2016) Animal water balance drives top-down effects in a riparian forest-implications for terrestrial trophic cascades. Proc R Soc B-Biol Sci 283(1836):1-8. https://doi.org/10.1098/rspb.2016.0881

McCluney KE (2017) Implications of animal water balance for terrestrial food webs. Curr Opin Insect Sci 23:13-21. https://doi.org/10.1016/j.cois.2017. 06.007

Muller-Navarra DC (2008) Food web paradigms: the biochemical view on trophic interactions. Int Rev Hydrobiol 93(4-5):489-505. https://doi.org/ 10.1002/iroh.200711046 
Nagai K, Yano E (2000) Predation by Orius sauteri (Poppius) (Heteroptera: Anthocoridae) on Thrips palmi Karny (Thysanoptera: Thripidae): functional response and selective predation. Appl Entomo Zool 35(4):565-574. https://doi.org/10.1303/aez.2000.565

Nakamura K (1977) A model for the functional response of a predator to varying prey densities based on the feeding ecology of wolf spiders. Bull Nat Inst Agric Sci 31:29-89

Nakata T (1995) Population fluctuations of aphids and their natural enemies on potato in Hokkaido. Jpn Appl Entomo Zool 30(1):129-138. https://doi. org/10.1303/aez.30.129

Obopile M (2006) Economic threshold and injury levels for control of cowpea aphid, Aphis craccivora Linnaeus (Homoptera: Aphididae) on cowpea. Afr Plant Prot 12:111-115

Power AG, Borer ET, Hosseini P, Mitchell CE, Seabloom EW (2011) The community ecology of barley/cereal yellow dwarf viruses in Western US grasslands. Virus Res 159(2):95-100. https://doi.org/10.1016/j.virusres. 2011.05.016

Pyke GH, Pulliam HR, Charnov EL (1977) Optimal foraging: a selective review of theory and tests. Q Rev Biol 52(2):137-154. https://doi.org/10.1086/ 409852

Raubenheimer D, Simpson SJ (2003) Nutrient balancing in grasshoppers: behavioural and physiological correlates of dietary breadth. J Exp Biol 206(10):1669-1681. https://doi.org/10.1242/jeb.00336

Raubenheimer D, Simpson SJ, Mayntz D (2009) Nutrition, ecology and nutritional ecology: toward an integrated framework. Funct Ecol 23(1):4-16. https://doi.org/10.1111/j.1365-2435.2009.01522.x

Reitz SR, Funderburk JE, Waring SM (2006) Differential predation by the generalist predator Orius insidiosus on congeneric species of thrips that vary in size and behavior. Entomol Exp Appl 119(3):179-188. https://doi.org/10. 1111/j.1570-7458.2006.00408.x

Schmidt JM, Sebastian P, Wilder SM, Rypstra AL (2012) The nutritional content of prey affects the foraging of a generalist arthropod predator. PLOS ONE 7(11):1-9. https://doi.org/10.1371/journal.pone.0049223

Shi SL, Liu XX, Zhang QW, Zhao ZW (2010) Morph-specific differences in metabolism related to flight in the wing-dimorphic Aphis gossypii. Insect Sci 17(6):527-534. https://doi.org/10.1111/j.1744-7917.2010.01332.x

Sih A, Christensen B (2001) Optimal diet theory: When does it work, and when and why does it fail? Anim Behav 61(2):379-390. https://doi.org/10.1006/ anbe.2000.1592

Simpson SJ, Raubenheimer D (2005) Obesity: the protein leverage hypothesis. Obes Rev 6(2):133-142. https://doi.org/10.1111/j.1467-789X.2005.00178.x

Simpson SJ, Raubenheimer D (2012) The nature of nutrition: a unifying framework from animal adaptation to human obesity. Princeton University Press, Princeton

Sterner RW, Elser JJ (2002) Ecological stoichiometry: the biology of elements from molecules to the biosphere. Princeton University Press, Princeton

Stoetzel M, Miller G (2001) Aerial feeding aphids of corn in the United States with reference to the root-feeding Aphis maidiradicis (Homoptera: Aphididae). Fla Entomol 84(1):83-98. https://doi.org/10.2307/3496667

Sun XH, Xu XN, Wang ED (2009) The prey preference of Orius sauteri on western flower thrips and two-spotted spider mite. Acta Ecol Sin 29(11):2685-2691

Tanaka Y, Narita R, Ohno T, Ogiso M (2002) Comparison of numbers of prey consumption and fertility about predatory bugs, Orius spp. Res Bull AichiKen Agric Res Center 34:99-104

Van Handel E (1969) Do trehalose and trehalase function in renal glucose transport? Science (new York, NY) 163(3871):1075-1076. https://doi.org/ 10.1126/science.163.3871.1075

Van Handel E (1985a) Rapid determination of glycogen and sugars in mosquitoes. J Am Mosq Control Assoc 1(3):299-301

Van Handel E (1985b) Rapid determination of total lipid in mosquitoes. J Am Mosq Control Assoc 1(3):302-304

Van Handel E, Day JF (1988) Assay of lipids, glycogen and sugars in individual mosquitos - correlations with wing length in field-collected Aedes vexans. J Am Mosq Control Assoc 4(4):549-550

Waldbauer G, Friedman S (1991) Self-selection of optimal diets by insects. Annu Rev Entomol 36(1):43-63. https://doi.org/10.1146/annurev.en.36. 010191.000355

Wang HL, Qin XF, Yu H, Wang GC (2013) Predation of Orius sauteri on MEAM1 Bemisia tabaci Pseudopupae. J Ecol Rural Environ 29(1):132-135
Wang S, Michaud JP, Tan XL, Zhang F (2014) Comparative suitability of aphids, thrips and mites as prey for the flower bug Orius sauteri (Hemiptera: Anthocoridae). Eur J Entomol 111(2):221-226. https://doi.org/10.14411/ eje.2014.031

Whelan CJ, Schmidt KA (2007) Food acquisition, processing, and digestion. In: Stephens DW, Brown JS, Yden RC (eds) Foraging: behavior and ecology. The University of Chicago Press, Chicago, pp 141-172

Wilder SM, Norris M, Lee RW, Raubenheimer D, Jordan SSJ, F, (2013) Arthropod food webs become increasingly lipid limited at higher trophic levels. Ecol Lett 16(7):895-902. https://doi.org/10.1111/ele.12116

Wong SC, Oksanen A, Mattila ALK, Lehtonen R, Niitepold K, Hanski I (2016) Effects of ambient and preceding temperatures and metabolic genes on flight metabolism in the Glanville fritillary butterfly. J Insect Physiol 85:23-31. https://doi.org/10.1016/j.jinsphys.2015.11.015

Yano E (1996) Biology of Orius sauteri (Poppius) and its potential as a biocontrol agent for Thrips palmi Karny. Bulletin OILB/SROP 19(1):203-206. In: Proceedings of the meeting Integrated control in glasshouses, Vienna, Austria, 20-25 May 1996

Yano E, Jiang NQ, Hemerik L, Mochizuki M, Mitsunaga T, Shimoda T (2005) Time allocation of Orius sauteri in attacking Thrips palmi on eggplant leaf. Entomol Exp Appl 117(3):177-184. https://doi.org/10.1111/j.1570-7458. 2005.00347.x

Zhang Y, Zhao MC, Cheng J, Liu S, Yuan HB (2020) Population dynamics and species composition of maize field parasitoids attacking aphids in northeastern China. PLoS ONE. https://doi.org/10.1371/journal.pone.0241530

Zhou GL, Flowers M, Friedrich K, Horton J, Pennington J, Wells MA (2004) Metabolic fate of [14C]-labeled meal protein amino acids in Aedes aegypti mosquitoes. J Insect Physiol 50(4):337-349. https://doi.org/10.1016/j.jinsp hys.2004.02.003

Zou WH (2004) The laboratory rearing and predatory capacity of the predatory bug, Orius sauteri (Poppius) (Heteroptera:Anthocoridae). Dissertation. Huazhong Agricultural University.

\section{Publisher's Note}

Springer Nature remains neutral with regard to jurisdictional claims in published maps and institutional affiliations.

\section{Submit your manuscript to a SpringerOpen ${ }^{\circ}$ journal and benefit from:}

- Convenient online submission

- Rigorous peer review

- Open access: articles freely available online

- High visibility within the field

- Retaining the copyright to your article

Submit your next manuscript at springeropen.com 